\title{
O PARRICÍDIO EM TOTEM E TABU: UMA ANÁLISE ACERCA DA GÊNESE DO CONCEITO DE PULSÃO DE MORTE
}

\author{
Le parricide em Totem et tabou: une analyse sur la \\ genèse du concept de pulsión de mort
}

Maria Vilela Pinto Nakasu ${ }^{1}$

Resumo

Preocupado com a questão das origens, Freud localizou na esfera cultural os fenômenos do ódio e da agressividade como sendo essenciais para fundamentar sua teoria social. Ao derivar de um crime contra o pai a origem da sociedade civilizada, da religião e da moral, dos desejos que compõem o complexo de Édipo e do que viria a ser o superego, ele conclui ser impossível pensar a cultura sem considerar as tendências destrutivas do homem e seus efeitos para a história da humanidade. Em que medida podemos afirmarque a reflexão freudiana sobre a cultura incide sobre a formulação e a consolidação de algumas noções metapsicológicas?Este trabalho se propõe a analisara influência das teses psicanalíticas apresentadas em Totem e tabu na gênese do conceito de pulsão de morte.

Palavras-chave: Freud; Pulsão de morte; Totem e tabu; Teoria da cultura.

1 Doutoranda em Filosofia. Univ. Fed. de São Carlos, UFSCAR, Brasil.

E-mail:marianakasu@hotmail.com

Revista de Filosofia, Curitiba, v. 17 n.20, p. 137-146, jan./jun. 2005. 


\section{Abstract}

Concerned with the matter of origins, Freud placed on the cultural sphere the phenomena of hatred and aggressiveness as being essential to give basis to his social theory. When deriving from a crime against the father the origin of civilized society, of religion and moral, of the desires that constitute the Oedipus complex and of what would later be the superego, he concludes it is impossible to think culture not taking into consideration man's destructive tendencies and their effects to the history of humanity. In what sense can we state that Freudian reflection on culture fall upon some metapsychological notions?This paper aims at analyzing the influence of the psychoanalytical ideas presented in Totem and Tabu on the genesis of death drive concept.

Keywords: Freud; Instinct destructive; Toten and Tabu; Theory of Culture.

\section{Introdução}

Em Totem e tabu (1914), como escreve Peter Gay (1988), Freud afasta-se da concretude de suas inferências clínicas para enveredar-se por um terreno até então pouco investigado por ele: o terreno da etnologia, da filologia e dos folcloristas. Para o biógrafo de Freud, Totem e tabu é psicanálise aplicada e também um documento político. Interessa-nos acompanhar a elaboração e a descrição freudiana da hipótese do mito da horda primitiva para analisarmos a pertinência da suposição segundo a qual as teses freudianas sobre o nascimento da cultura e das instituições sociais contribuíram para a elaboração do conceito de pulsão de morte.

Em uma carta a Ernest Jones, Freud (1913) tece o seguinte comentário a respeito de Totem e tabu: "Naquela época - da redação da interpretação dos sonhos - descrevi o desejo de matar o próprio pai, mas agora descrevi o homicídio efetivamente realizado; de qualquer maneira, é um gigantesco passo a frente - do desejo ao fato" (JONES, 1979, p. 440). Discutiremos as conseqüências deste "passo a frente" para os conceitos de ódio e de agressividade e sustentaremos que a elaboração de uma primeira ocorrência real e prototípica para as experiências de ódio parece ter estendido a relevância de tais conceitos no arcabouço teórico da psicanálise, tendo influenciado nas condições de surgimento da segunda teoria das pulsões e, sobretudo, do conceito de pulsão de morte. 


\section{Desenvolvimento}

A pesquisa analítica em torno da noção de tabu é o ponto de partida de uma reflexão que revela a intensidade das tendências homicidas e incestuosas entre os homens primitivos. A tese freudiana segundo a qual a civilização repousa sobre a coerção das pulsões, apresentada em A moral sexual civilizada e o nervosismo moderno (1908), é novamente anunciada no contexto sobre o tabu (FREUD, 1989). Este é considerado, ao lado dos sintomas obsessivos, um meio eficaz de coagir as pulsões e de impedir o livre curso das tendências inconscientes homicidas e incestuosas. Na relação dos selvagens com os inimigos, governantes e mortos, a atitude ambivalente frente aos impulsos de morte estaria presente ao lado do outro pólo da ambivalência emocional, governado por sentimentos amorosos, ternos e de admiração (FREUD, 1913). Totem e tabu (1913) relaciona de forma muito clara, no quarto ensaio, a noção de ambivalência à de complexo de Édipo, mas já no primeiro é introduzida a idéia de que as proibições e as leis - tal como a lei de proibição do incesto - são proporcionais à intensidade do desejo de transgredi-las.

Na relação dos selvagens com os inimigos, a ambivalência de sentimentos aparece na forma de luto e de arrependimento; na relação com os governantes ela aparece na forma de respeito, por um lado, e de hostilidade inconsciente, por outro; frente aos mortos, os selvagens sofreriam conscientemente, mas se satisfariam inconscientemente. Os dois sentimentos contraditórios, um consciente e o outro inconsciente, estariam, por assim dizer, sempre presentes. A necessidade das proibições do tabu e dos rituais estaria, portanto, a serviço do desejo intenso de matar e do conseqüente repúdio a este desejo. Ouçamos o próprio Freud (1913): "Teremos que concluir que os primitivos se acham literalmente perseguidos pela tentação de matar seus reis e sacerdotes, cometer incestos e maltratar seus mortos (...) A tendência de matar é, em nós, mais forte do que cremos, e se manifesta por efeitos psíquicos, mesmo se escapam à consciência (...) Esta tendência existe realmente no inconsciente, e o tabu, como mandamento moral, explica-se e se justifica por uma atitude ambivalente quanto ao impulso homicida" (FREUD, 1989, p. 160).

Para argumentar em favor da idéia de que o sistema totemista resulta das condições em jogo no complexo de Édipo, são resgatados dois exemplos clínicos de crianças que incluíam animais nos seus sintomas: o caso do pequeno Hans e do Arpád, relatado por Ferenczi. Hans

Revista de Filosofia, Curitiba, v. 17 n.20, p. 137-146, jan./jun. 2005. 
temia ser mordido por cavalos, e Arpád identificava-se com galos e galinhas, acreditando ser um deles, além de manter o hábito de matar os animais e de dançar ao seu redor num gesto de comemoração. Em sua Autobiografia, Freud (1925) relembra o ponto comum observado nos casos clínicos infantis e na relação dos selvagens com o totem: "Em seguida vieram em meu auxílio dois fatos da psicanálise: uma feliz observação de Ferenczi de uma criança (1913), que me permitiu falar do retorno do totemismo da infância e a análise das precoces zoofobias das crianças; esta análise demonstrou que o animal era um substituto do pai, e sobre o animal se havia deslocado o medo deste último, fundado no Complexo de Édipo" (FREUD, 1989). ${ }^{2}$ Não matar o totem e não se casar com a mulher do mesmo clã totêmico coincidia com os dois crimes do Édipo, que matou o pai e se casou com a mãe; coincidência que resultou na conclusão de que assim como a zoofobia de Hans e a perversão de Árpad, o sistema totemista também resultava das condições em jogo no complexo de Édipo.

O próximo passo foi analisar a aparente incoerência dos clãs no banquete totêmico: eles diziam descender do totem e, ao mesmo tempo, mantinham o hábito de comê-lo. Este ato foi interpretado por Freud como uma tentativa dos membros do clã de se identificarem com 0 totem para adquirirem um pouco de sua força, ato que parecia revelar entre os selvagens, mais uma vez, a presença da ambivalência e dos desejos edipianos. Freud (1913) retoma a teoria darwiniana do estado primitivo da sociedade humana ${ }^{3}$ e se pergunta se a forma de organização totêmica desenvolveu-se a partir de outras (FREUD, 1989). Em seguida, recupera a celebração da refeição totêmica e a interpretação psicanalítica do totem, e anuncia uma hipótese, a qual denomina "mito científico"; hipótese que também havia sido alcançada por Atkinson (1903) como implicação direta do estado de coisas da horda primeva darwiniana. Ei-la: os irmãos, expulsos pelo pai violento e temido, retornam, matam-no e o devoram, colocando fim à horda patriarcal. $\mathrm{O}$ ato de devorar o pai consuma a identificação dos irmãos com ele, que adquirem parte de sua força. A refeição totêmica, diz Freud (1913), “(...) que é talvez o

2 Autobiografia (1920).

3 Embora não fale dos primórdios do totemismo, segundo a teoria de Darwin existia um pai ciumento e violento que guardava as fêmeas para si e expulsavam os filhos quando estes cresciam. 
O parricídio em Totem e Tabu uma análise acerca da gênese do conceito de pulsão de morte

mais antigo festival da humanidade, seria assim uma repetição, e uma comemoração desse ato memorável e criminoso, que foi o começo de tantas coisas: da organização social, das restrições morais e da religião" (FREUD, 1989, p. 145). O "mito científico" termina com o arrependimento dos irmãos. Tendo sido posto em prática o ódio paterno por sua morte, a afeição até então recalcada veio à tona produzindo um enorme sentimento de culpa. Surge entre os irmãos um ideal que corporifica o poder ilimitado do pai primevo e a disposição de se submeterem a ele. 0 pai morto torna-se, desta forma, mais poderoso do que quando estava vivo, e a interdição sexual com mulheres do mesmo clã, antes estabelecida pelo pai, passa a ser determinada e seguida espontaneamente pelos irmãos (FREUD, 1913).

O mito da horda primitiva procura explicar a origem das tendências inconscientes homicidas e dos desejos incestuosos constitutivos do complexo de Édipo. A idéia de que os irmãos foram tomados pelos mesmos sentimentos contraditórios em ação no complexo de Édipo, manifestado pelos pacientes neuróticos, encobre uma conclusão ainda mais fundamental: a de que os irmãos não foram invadidos pelos sentimentos edipianos que os levaram à ação, mas de que o assassinato teria fundado tais sentimentos. O mito da horda explicaria, desta forma, 0 surgimento dos desejos edipianos e não o inverso. Em relação a isto, Mezan (1997) diz o seguinte: "O crime não corresponde aos desejos edipianos; mas estes são estruturados por ele. Matar o pai e dormir com a mãe são tendências que existem no inconsciente sob a forma de repressão, e esta, praticamente, é instituída a partir do crime, e não o inverso. A originalidade freudiana consiste em associar a emergência do complexo de Édipo e o surgimento da sociedade civilizada por meio do mesmo ato" (MEZAN, 1997, p. 356). O mito da horda é, por essa razão, extremamente relevante para a teoria freudiana: ele esclarece o nascimento do complexo de Édipo, complexo estruturante da personalidade e, sobretudo, permite a Freud justificar o ato que teria originado a cultura. Não se trata aqui de discutir a pertinência e a validade desta teoria no contexto do debate antropológico mais geral. Interessa-nos apenas sublinhar que a escolha do parricídio como ato fundante da civilização possibilitou ao fenômeno da destrutividade ampliar sua relevância no rol dos fenômenos investigados por Freud. $\mathrm{O}$ acento sobre a natureza cruel do homem, presente na cena do assassinato, parece ter deslocado a idéia de destruição e morte, até então restritas ao domínio da psicopatologia para

Revista de Filosofia, Curitiba, v. 17 n.20, p. 137-146, jan./jun. 2005. 
o terreno da cultura. Ao pressupor que o estado de cultura surge de um assassinato, e que este crime resultou na formação dos grupos e das normas sociais, Freud parece ampliar a relevância do conceito. Ao mesmo tempo, elabora uma previsão, retomada nos últimos textos culturais, de que a marca da violência e da destruição é inerente à história do homem e ao seu funcionamento psíquico, na medida em que seus traços permeiam as atividades humanas e as realizações culturais. $\mathrm{O}$ que pode ser compreendido como previsão com relação ao futuro do homem em Totem e tabu, se torna em O mal-estar na civilização (1937) um fato (FREUD, 1989).

No final do texto antropológico, Freud sustenta que a eliminação do pai primevo pelos filhos deixou traços inerradicáveis na histónia da humanidade, e quanto menos estes traços foram relembrados, mais substitutos originaram. A herança de disposições psíquicas que teriam sido despertadas na vida do indivíduo justificaria a passagem da carga emocional de uma geração para outra. Os indivíduos modernos, nesse sentido, viveriam repetindo os traços deixados pelo ato fundante da civilização. E, finalmente, os desejos inconscientes incestuosos e hostis, bem como o sentimento inconsciente de culpa, residiriam nos principais legados do parricídio.

Até o momento da publicação de Totem e Tabu (1913), os fenômenos destrutivos exerciam um papel relevante na formação do complexo de Édipo. Sabemos que na obra dedicada aos sonhos, de 1900, vem a público a idéia de que os primeiros sentimentos despertados nas crianças com relação aos pais são sentimentos de ódio e amor. As noções de complexo de Édipo e de ambivalência já atribuíam um lugar determinante na estruturação do psiquismo humano às moções de sentimentos hostis (FREUD, 1900). No caso Dora, Freud (1905) fracassa por não ter analisado a transferência negativa da paciente que se colocou como um obstáculo à continuidade do tratamento (FREUD, 1989). Nos Três ensaios de 1905), ele esboça uma teoria da perversão que, mais tarde, é retomada em Pulsões e seus destinos (1915), na conceituação do sadismo e do masoquismo (FREUD, 1989). Os desejos inconscientes homicidas, os fenômenos destrutivos de maneira geral, até a publicação de Totem e Tabu, já haviam sido tomados em consideração na análise psicanalítica do indivíduo normal, bem como no campo específico da psicopatologia freudiana. No entanto, a suposição segundo a qual os desejos edipianos, o superego, a sociedade civilizada, a moral - externa e internalizada - , a 
O parricídio em Totem e Tabu uma análise acerca da gênese do conceito de pulsão de morte

religião e a arte originaram-se do assassinato paterno eleva a natureza destrutiva do homem a um patamar até então pouco explorado: reafirma que a destrutividade é uma tendência natural do homem, localizando-a, desta vez, nas produções culturais e no campo das relações compartilhadas. A maldade e a agressividade humana saem do campo clínico e do terreno dos fenômenos normais individuais para ingressarem no campo da cultura e da pré-história do indivíduo. Neste movimento, 0 alcance da noção de destrutividade parece ampliar-se. A hipótese de que a cultura e todas as instituições e contratos sociais descendem de um crime acrescenta à idéia de homem um ingrediente importante: este homem não é apenas portador de tendências destrutivas que se expressam nos sintomas ou em suas inclinações sexuais, nem o sujeito de atuações contra o terapeuta no contexto do setting analítico e em suas relações interpessoais.

Ele herdou e repete uma carga de destrutividade cuja origem lhe é desconhecida; pertence a uma cultura cujo ato fundante foi um assassinato, e precisa se submeter à leis internas e a uma instância psíquica que o impede de extravasar sua agressividade, gerando culpa. Do mesmo modo, este homem se submete a leis externas que o impede de ser violento, leis que foram criadas justamente para frear seu desejo e suas tendências violentas. Além disso, ele sublima a agressividade e contribui para a geração do patrimônio cultural. Sob a égide do cristianismo, que segundo Freud originou-se do sistema totêmico, idealiza um pai que o castiga quando desobedecido, e que o protege quando obedecido, sempre lhe oferecendo uma vida melhor após a morte. Ao identificar a destrutividade no plano do nascimento da cultura, no plano das regras de funcionamento da cultura, e no plano das regras de funcionamento do psiquismo, Freud parece ampliar o alcance deste conceito, concedendo-lhe um lugar central na explicação dos fenômenos culturais.

Enriquez (1990), apoiando-se em Totem e tabu, emite uma opinião semelhante com relação ao impacto do assassinato primordial para a teoria freudiana da cultura e sua relação com os fundamentos do conceito de pulsão de morte. Vale a pena reproduzi-la, aqui, integralmente.

Essa obra marca não apenas uma descentralização do olhar do analista (até então centrado no indivíduo), em direção ao "socius", mas principalmente o aparecimento de uma teoria radicalmente pessimista, fazendo a humanidade nascer de um crime cometido em conjunto,

Revista de Filosofia, Curitiba, v. 17 n.20, p. 137-146, jan./jun. 2005. 
crime do qual a humanidade não pode jamais se liberar. Assim, 0 primeiro crime não é senão o prelúdio de uma série ininterrupta de assassinatos, que parece ser o corolánio normal da existência humana em sociedade. Não existe mais a esperança de um destino feliz para a comunidade humana associado a um desenvolvimento harmonioso da sexualidade. Ao assinar Totem e Tabu (bem antes de formular explicitamente a hipótese de uma pulsão de morte), Freud enterra definitivamente a idéia (que será mantida por Reich contra todos e contra tudo) da liberação possível do indivíduo pelo ato de assumir sua sexualidade genital, assim como a teoria da maturação do indivíduo através de sua aceitação, realização e sublimação das pulsões sexuais, idéias que obcecam, em maior ou menor grau, a prática psicanalítica, mesmo que o discurso que o acompanha enuncie explicitamente 0 contrário.

Enriquez (1990) reconhece que o crime gerou conseqüências tais que a sociedade não pode ser compreendida sem, no entanto, considerar que a natureza humana é portadora de um impulso destrutivo e irrefreável. A questão da incoercibilidade das pulsões é também sublinhada por Wladimir Grannof, apud Mezan (1997), para quem o ponto central de Totem e Tabu reside na incoercibilidade do desejo de matar o pai. A tese de que as pulsões sexuais são irrefreáveis, irreprimíveis e que trazem más conseqüências ao bem-estar subjetivo do homem já estava presente nas formulações culturais de A moral civilizada e o nervosismo moderno. Neste texto, o ônus psíquico gerado pela renúncia do pulsional é significativo e o mal-estar subjetivo e o aumento da agressividade são considerados a contrapartida do desenvolvimento da cultura (FREUD, 1908). Entretanto, a visão baseada na idéia de que a felicidade humana é possível desde que se reprima menos a sexualidade é modificada se nos determos na concepção de Totem e Tabu. Nela, os impulsos destrutivos não podem ser totalmente reprimidos, além de gerarem um ônus psíquico enorme. Além disso, o que está em jogo em Totem e tabu é o acento sobre a repressão das moções pulsionais agressivas, e não mais da repressão sexual. Este texto inaugura a discussão sobre o impacto da repressão das pulsões destrutivas na vida em sociedade; tema que volta a ser discutido em $\mathrm{O}$ mal-estar na civilização, sobretudo na teorização da questão da internalização da agressividade na forma de sentimento de culpa.

Revista de Filosofia, Curitiba, v. 17 n.20, p. 137-146, jan./jun. 2005. 
Considerações finais

Realizamos essa discussão apenas para argumentar em favor da tese de que a análise freudiana da cultura produz efeitos sobre sua formulação de algumas noções metapsicológicas. Totem e tabu parece desempenhar um papel relevante e, quiçá, determinante na ampliação do conceito de destrutividade. Sabemos, e isso é consensual entre os comentadores de Freud, que a segunda teoria pulsional veio ao encontro da necessidade de se acomodar a noção de destrutividade de modo a lhe conceder um lugar de maior destaque à altura de sua relevância no plano da clínica. Acrescentamos, feito esse percurso, que a noção de pulsão de morte também acomodou os fenômenos destrutivos à altura de sua relevância no plano da cultura.

Além do princípio do prazer (1920), ao retirar o componente agressivo das pulsões sexuais e das pulsões de autoconservação, e ao unir estas duas pulsões entre si, Freud concebe Eros. O componente agressivo desloca-se para um grupo inteiro de pulsões por ele denominada "pulsões de morte" (FREUD, 1989). É justamente esta manobra conceitual que lhe permite ampliar o lugar destinado às tendências e comportamentos destrutivos na metapsicologia. Mesmo considerando o fato de que estas tendências e comportamentos passam a ser justificados a partir da fusão das pulsões de morte e Eros, a partir de 1920, as pulsões de morte são eleitas a fonte pulsional por excelência de tais fenômenos. Aqui sustentamos, portanto, que Totem e tabu, ao ampliar o lugar destinado aos fenômenos destrutivos no arcabouço psicanalítico, contribuiu para a elaboração de um conceito que contemplasse a natureza mortífera do homem, dando-lhe o devido lugar de destaque que a clínica, a psicologia do indivíduo e a psicologia social de Freud já haviam concedido, ainda que no plano das observações e especulações. Parece que a investigação cultural de Freud contribuiu decisivamente para a formulação do conceito de pulsão de morte, exemplar da solidariedade entre as reflexões "metapsicologia" e "teoria da cultura". Conseqüentemente, nos aventuramos a sustentar a tese segundo a qual as incursões freudianas pela cultura incidem sobre a reflexão metapsicológica, provocando efeitos sobre a formulação de suas noções.

Revista de Filosofia, Curitiba, v. 17 n.20, p. 137-146, jan./jun. 2005. 
Referências

FREUD, S. Além do princípio do prazer. In: OBRAS Completas. Buenos Aires: Amorrortu, 1989. v. 18. Publicado originalmente em 1920.

. Autobiografia. In: OBRAS Completas. Buenos Aires: Amormortu, 1989. v. 20. Publicado originalmente em 1920.

. A interpretação dos sonhos. In: OBRAS Completas. Buenos Aires: Amorrortu, 1989. v. 4-5. Publicado originalmente em 1900.

. A moral sexual civilizada e o nervosismo modemo. In: OBRAS completas. Buenos Aires: Amorrortu, 1989. v. 9. Publicado originalmente em 1908.

. Fragmento de análise de um caso de histeria. In: OBRASCompletas. Buenos Aires: Amorrortu, 1989. v. 7. Publicado originalmente em 1901/05).

. O mal-estar na civilização. In: OBRASCompletas. Buenos Aires: Amorrortu, 1989. v. 21. Publicado originalmente em 1930.

. Pulsões e destinos das pulsões. In: OBRAS Completas. Buenos Aires: Amorrortu, 1989. v. 14. Publicado originalmente em 1915.

. Totem e tabu. In: OBRAS Completas. Buenos Aires: Amorrortu, 1989. v. 13. Publicado originalmente em 1912/13.

. Três ensaios sobre a teoria sexual. In: OBRASCompletas. Buenos Aires: Amorrortu, 1989. v. 7. Publicado originalmente em 1905.

ENRIQUEZ, E. Da horda ao estado. Rio de janeiro, RJ: Jorge Zahar, 1990. JONES, E. Vida e obra de Sigmund Freud. Rio de Janeiro, RJ: Guanabara, 1979.

MEZAN, R. Freud, o pensador da cultura. São Paulo,SP: Brasiliense, 1997.

Apoio: FAPESP - Fundação de Amparo à Pesquisa do Estado de São Paulo. Agradecimento: Primo Renan Nogueira de Araújo.

Recebido em: Received in: 22/02/ 2005 Aprovado em: Approved in: 23/03/2005 